\title{
Photoinduced Charge Transfer
}


This page is intentionally left blank 


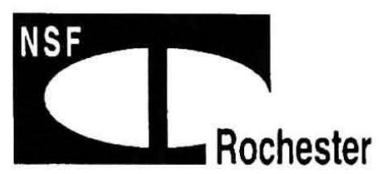

\section{PhotolnducED}
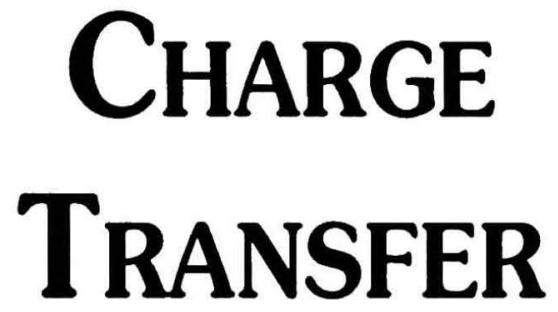

University of Rochester, Rochester, New York

$26-29$ July 1999

Editor

\section{Lewis Rothberg}

University of Rochester, Rochester, New York 


\section{Published by}

World Scientific Publishing Co. Pte. Ltd.

P O Box 128, Farrer Road, Singapore 912805

USA office: Suite 1B, 1060 Main Street, River Edge, NJ 07661

UK office: 57 Shelton Street, Covent Garden, London WC2H 9HE

\section{British Library Cataloguing-in-Publication Data}

A catalogue record for this book is available from the British Library.

\section{PHOTOINDUCED CHARGE TRANSFER}

Copyright $(\odot) 2000$ by World Scientific Publishing Co. Pte. Ltd.

All rights reserved. This book, or parts thereof, may not be reproduced in any form or by any means, electronic or mechanical, including photocopying, recording or any information storage and retrieval system now known or to be invented, without written permission from the Publisher.

For photocopying of material in this volume, please pay a copying fee through the Copyright Clearance Center, Inc., 222 Rosewood Drive, Danvers, MA 01923, USA. In this case permission to photocopy is not required from the publisher.

ISBN $981-02-4267-0$

Printed in Singapore by Regal Press (S) Pte. Ltd. 


\section{PREFACE}

The present volume is the proceedings of the Tenth International Conference on Photoinduced Charge Transfer held at the University of Rochester and sponsored by the National Science Foundation Center for Photoinduced Charge Transfer along with Eastman Kodak and Xerox corporations. The meeting provided a retrospective on accomplishments in the area of photoinduced charge transfer and a snapshot of the current state of the art. The proceedings volume is intended not only as a reference to cutting edge work but as a tribute to the contributions of the NSF Center established in 1988 and now in its final year of NSF funding as mandated under the Science and Technology Center umbrella. It is our sincere hope that the Center has served as a focal point for many of the advances and innovations in photoinduced charge transfer in the past decade.

Work in the Center has focussed primarily on the underlying chemistry and physics of electrophotography and photography. This has entailed extensive work on the photophysics of donor-acceptor complexes, photoinitiated radical ion chemistry, charge generation and transport in disordered organic materials, effects of molecular aggregation on optical properties and charge transfer at interfaces. All of these topics are heavily represented in the present volume and ordered approximately as described above.

In addition, the NSF Center contributed heavily to the educational mission of the University of Rochester and the scientific literacy of the local community. We have initiated and sponsored a variety of outreach programs, and are proud of the impact we have had. It seemed fitting to present this work as part of the conference and codify it in the proceedings. The second paper by Uzelmeier and Kampmeier describes some of our efforts in the educational arena and we hope that it is also beneficial in spurring further work based on our experience.

Finally, the Center and its students have been blessed over the past decade with strong participation of colleagues in industry without which we could not have created the problem rich interdisciplinary environment in which our educational and research programs thrive. We commence the volume with a tribute to our recently deceased beloved colleague, Paul Borsenberger of Eastman Kodak, whose contributions to the science of charge transport in organic materials and to the Rochester community are deeply appreciated. 
It is our sincere hope that this volume will be of value in advancing and disseminating the knowledge our community has gained in the past decade.

Lewis Rothberg

Director, NSF Center for Photoinduced Charge Transfer

December 1999. 


\section{CONTENTS}

Preface

Dr. Paul M. Borsenberger (1935-1998) - A Research Retrospective David S. Weiss

Educational Outreach Programs at the Center for Photoinduced Charge

Transfer: Learning Through Research

Calvin E. Uzelmeier and Jack A. Kampmeier

Intramolecular Radical Ion Pairs in the Photochemistry of 2-Arylethyl Esters

J. A. Pincock, S. Rifai and R. Stefanova

External Electric Field Effects on Fluorescence of Some Methylene-Linked Compounds of Electron Donor and Acceptor in a Polymer Film

Nobuhiro Ohta, Takayuki Kanada, Hiroshi Kawabata,

Yoshinobu Nishimura, Iwao Yamazaki, Masahide Yamamoto,

Michiya Itoh and Kaoru Iwai

Function Modulation in a Heterosupramolecular Assembly

Geoffrey Will, Gerrit Boschloo, Robin Hoyle, S. Nagaraja Rao

and Donald Fitzmaurice

Excitons in Pinwheel Aggregates of $\pi$-Conjugated Molecules

F. C. Spano and S. Siddiqui

Optical Signature of $\pi$-Stacking in Conjugated Polymers and Oligomers:

Effects of Molecular Structure and Solid State Morphology

M. David Curtis

Engineering of Sidegroups to Enhance Luminescence Efficiency of

Conjugated Polymers

Rachel Jakubiak, Chris Collison, Lewis Rothberg,

Wai Chou Wan, Bing Hsieh and Zhenan Bao 
How to Calculate the Carrier Drift Mobility in Disordered Organic Materials Containing Traps: A Message from the Computer Experiment to the Real One

S. V. Novikov, D. H. Dunlap and V. M. Kenkre

Growth Modes and Charge Injection of Organic Films on Standard and Ultraflat Indium Tin Oxide

E. W. Forsythe, M. A. Abkowitz and Yongli Gao

Localized and Delocalized Electronic Excitations in Biological and Artificial Antenna Complexes

Sergei Tretiak, Chris Middleton, Vladimir Chernyak and Shaul Mukamel

Polymer 3D Nanocomposites: New Routes to Development

Olga Kalinina, Eugenia Kumacheva, Bradley Siwick and R. J. Dwayne Miller

Investigation of Several Cholesterol-Stilbene Organogels: An Attempt to Correlate the Photophysical Behavior to the Structure of the Gelator

Cristina Geiger, Rong Wang and David G. Whitten

Structure and Properties of Aggregates Formed by Self-Assembly of Amphiphiles and Related Species

David G. Whitten, Jerry Perlstein, Cristina Geiger,

Kangning Liang, Liangde Lu, Thomas L. Penner,

Steen Rasmussen, Liaohai Chen and Kock-Yew Law

Advances in Photoinduced Electron Transfer at Surfaces: A Decade in Perspective

R. J. Dwayne Miller

Snapshots of Electronic Surface Excitation: Observing Adsorbate

Dynamics with Femtosecond Time-Resolution

M. Bauer, S. Pawlik and M. Aeschlimann 
Femtosecond Excited State Dynamics in Organic Molecular Films

A. J. Mäkinen, S. Schoemann, Y. Gao, M. G. Mason, A. A. Muenter,

D. A. Mantell, A. R. Melnyk and R. L. Headrick

A Direct Measurement of Intermolecular Solvation Dynamics Using Time-Resolved THZ Spectroscopy (TRTS)

Gordon M. Turner, Matthew C. Beard, Dean S. Venables and

Charles A. Schmuttenmaer 